\title{
Horta Sustentável: Projeto estratégico de ensino como proposta na Educação
}

\section{Ambiental}

\author{
Sustainable Garden: Strategic teaching project as proposed in Environmental Education
}

Huerta Sustentable: Proyecto didáctico estratégico como propuesta en Educación Ambiental

Recebido: 18/01/2022 | Revisado: 26/01/2022 | Aceito: 03/02/2022 | Publicado: 05/02/2022

Fabio José Antônio da Silva

ORCID: https://orcid.org/0000-0002-5881-6438

Universidade Estadual de Londrina, Brasil

E-mail: fjas81@hotmail.com

Fernando Icaro Jorge Cunha

ORCID: https://orcid.org/0000-0002-0064-4039

Universidade Federal do Pampa, Brasil

E-mail: icaro729@gmail.com

Érica Paula Borri Bezerra

ORCID: https://orcid.org/0000-0003-3735-6839

Result Soluções Educacional, Brasil

E-mail: profericaborri@gmail.com

Katiane de Carvalho Lima

ORCID: https://orcid.org/0000-0002-3615-9043 Secretaria de Estado da Educação do Distrito Federal, Brasil

E-mail: katiane.lima@gmail.com

Daniela Ribeiro dos Santos

ORCID: https://orcid.org/0000-0002-6024-6091

Must University, Estados Unidos da América

E-mail: den.ensino@gmail.com

Vanessa de Oliveira Gaudereto Guimarães

ORCID: https://orcid.org/0000-0001-6691-2836

Instituto Guaicuy - SOS Rio das Velhas, Brasil

E-mail: vanessaogaudereto@gmail.com

Abdianne de Macedo Cavalcanti

ORCID: https://orcid.org/0000-0003-4632-8370 Universidade Federal do Vale do São Francisco, Brasil

E-mail: abdianne@gmail.com

Lilia de Oliveira Silva

ORCID: https://orcid.org/0000-0003-2431-8454

Rede Estadual de Ensino de Mato Grosso, Brasil

E-mail: lilia_pedagogabg@hotmail.com

Ricardo Santos de Almeida

ORCID: https://orcid.org/0000-0003-1266-2557

Universidade Federal de Santa Maria, Brasil

E-mail: ricardosantosal@gmail.com

Joana Maristela Moreira Moleda

ORCID: https://orcid.org/0000-0003-1538-7749

Rede de Ensino Municipal e Estadual de Uruguaiana, Brasil

E-mail: moleda.jo@gmail.com

Ariel Costa dos Santos

ORCID: https://orcid.org/0000-0002-0482-3827

Universidade Federal da Grande Dourados, Brasil

E-mail: ariel.costa.geo@gmail.com

\section{Resumo}

O presente trabalho teve por objetivo relatar os processos e resultados de um projeto de horta sustentável desenvolvido num espaço educacional sustentável aplicado com práticas de ensino, de forma que permitiu o uso de diversas abordagens que favoreceu a construção de conhecimentos teóricos e práticos relacionados à questões de sustentabilidade, meio ambiente e alimentação saudável como estratégia na educação ambiental com o incentivo à mobilização rumo à disseminação e multiplicação de informação em nossa sociedade que é um dos primeiros passos para a construção de um processo educativo. E através disso, foi possível obter resultados através de observações e intervenções de ações que contribuíram para que o ensino de Ciências proporcionasse condições para que alunos conhecessem e compreendessem a realidade em que se encontram inseridos. O projeto teve participação direta dos alunos onde foram responsáveis pelo resultado satisfatório por apresentar melhora no processo de ensino e 
aprendizagem por meios de conhecimento proporcionado, mudanças de hábitos ao longo desse projeto, como a conscientização da importância do reaproveitamento, reciclagem e a redução de materiais recicláveis utilizados, bem como a busca pela qualidade de vida, o bem-estar e a preservação do meio ambiente. Nesse contexto é importante ressaltar que com a execução do projeto foi possível construir maior aproximação entre as aulas teóricas e práticas utilizadas diante das habilidades adquiridas, conhecimentos sobre a importância de se obter uma técnica de manejo para uma alimentação saudável e livre da utilização de produtos agrotóxicos, focando no desenvolvimento dentre as disciplinas, atingindo a colaborar uma transformação interdisciplinar e a inclusão social.

Palavras-chave: Canteiros ecológicos; Sustentabilidade; Interdisciplinaridade.

\begin{abstract}
The present work aimed to report the processes and results of a sustainable garden project developed in a sustainable educational space applied with teaching practices in a way that allowed the use of different approaches that favored the construction of theoretical and practical knowledge related to sustainability issues, environment and healthy eating as a strategy in environmental education, encouraging mobilization towards the dissemination and multiplication of information in our society, which is one of the first steps towards building an educational process. And through that, it was possible to obtain results through observations and interventions of actions that contributed to the teaching of Science, which made it possible for students to know and understand the reality in which they are inserted. The project had direct participation of the students where they were responsible for the satisfactory result for presenting improvement in the teaching and learning process by means of provided knowledge, changes in habits throughout this project, such as the awareness of the importance of reuse, recycling and the reduction of materials recyclables used, as well as the search for quality of life, well-being and preservation of the environment. In this context, it is important to emphasize that with the execution of the project it was possible to build a closer relationship between the theoretical and practical classes used in the face of the acquired skills, knowledge about the importance of obtaining a management technique for a healthy diet and free from the use of pesticides., focusing on the development among the disciplines, reaching to collaborate an interdisciplinary transformation and social inclusion.
\end{abstract}

Keywords: Ecological gardens; Sustainability; Interdisciplinary.

\title{
Resumen
}

El presente trabajo tuvo como objetivo relatar los procesos y resultados de un proyecto de huerta sustentable desarrollado en un espacio educativo sustentable aplicado con prácticas docentes de manera que permitió el uso de diferentes enfoques que favorecieron la construcción de conocimientos teóricos y prácticos relacionados con temas de sustentabilidad, medio ambiente. y la alimentación saludable como estrategia en la educación ambiental, fomentando la movilización hacia la difusión y multiplicación de información en nuestra sociedad, que es uno de los primeros pasos para la construcción de un proceso educativo. Y a través de eso, fue posible obtener resultados a través de observaciones e intervenciones de acciones que contribuyeron a la enseñanza de las Ciencias, lo que posibilitó que los estudiantes conozcan y comprendan la realidad en la que están insertos. El proyecto contó con la participación directa de los estudiantes donde ellos fueron los responsables del resultado satisfactorio al presentar mejora en el proceso de enseñanza aprendizaje por medio de los conocimientos brindados, cambios de hábitos a lo largo de este proyecto, como la concientización de la importancia de reutilizar, reciclar y la reducción de materiales reciclables utilizados, asî como la búsqueda de la calidad de vida, el bienestar y la preservación del medio ambiente. En este contexto, es importante resaltar que con la ejecución del proyecto se logró construir una relación más estrecha entre las clases teóricas y prácticas utilizadas de cara a las habilidades adquiridas, conocimientos sobre la importancia de obtener una técnica gerencial para un alimentación saludable y libre del uso de pesticidas, enfocándose en el desarrollo entre las disciplinas, llegando a colaborar en una transformación interdisciplinaria e inclusión social.

Palabras clave: Parterres ecológicos; Sustentabilidad; Interdisciplinariedad.

\section{Introdução}

Para barrar a degradação ambiental a nível local e global, Capra (2004) defende que o grande desafio agora é criar comunidades sustentáveis - ambientes sociais e culturais onde os seres humanos podem satisfazer as necessidades e aspirações sem diminuir as chances das gerações futuras. Ele pontua que em qualquer sistema vivo existem relações de interdependência entre seus componentes, de cooperação generalizada, de reciclagem da matéria, tendendo sempre ao equilíbrio. O Art. $3^{\circ}$ - da Lei $n^{\circ}$ 6.938, de 31 de agosto de 1981, que dispõe sobre a Política Nacional do Meio Ambiente, define meio ambiente nos seguintes termos: 
Art. $3^{\circ}$ Para os fins previstos nesta Lei, entende-se por: I - meio ambiente, o conjunto de condições, leis, influências e interações de ordem física, química e biológica, que permite, abriga e rege a vida em todas as suas formas (Brasil, 1988).

E ainda pode ser observado nos artigos 1 e 2 da lei nº 9795/99, que dispõe sobre a educação ambiental:

Art. 1ำ - Entendem-se por educação ambiental os processos por meio dos quais o indivíduo e a coletividade constroem valores sociais, conhecimentos, habilidades, atitudes e competências voltadas para a conservação do meio ambiente, bem de uso comum do povo, essencial à sadia qualidade de vida e sua sustentabilidade. Art. 2o - A educação ambiental é um componente essencial e permanente da educação nacional, devendo estar presente, de forma articulada, em todos os níveis e modalidades do processo educativo, em caráter formal e não formal (Brasil, 1988).

Atualmente muitos Órgãos Gestores das políticas públicas estão mobilizando o sistema de ensino brasileiro para trabalhar com o tema Educação Ambiental, pois "educar para a cidadania é construir a possibilidade da ação política, no sentido de contribuir para formar uma coletividade responsável pelo mundo que habita" (Carvalho, 1991). Assim, para formar uma sociedade comprometida com. a vida na terra temos a educação como um dos pilares fundamentais na construção do desenvolvimento sustentável (Gomes, 2006).

Através da execução das aulas práticas expostas, os alunos conseguem ter maior compreensão do que foi lhe apresentado nas aulas teóricas e consequentemente conseguem construir caminhos para novas descobertas de aprendizagem, desenvolvendo a capacidade de transformar sua realidade social e possibilitando visar comportamentos individuais e coletivos. Cidadania, alimentação saudável e até cooperação são temas relacionados ao processo (Feiffer, Cunha, Benites \& Dinardi, 2022). "Se a criança vê a questão ambiental na escola, não como discurso, mas como ação, isso vai fazer sentido para ela. É preciso mostrar no dia a dia" (Carpegiani, 2015).

Em virtude do crescimento populacional, os problemas ambientais vêm despertando grandes preocupações, principalmente pelo acúmulo da quantidade de resíduos produzidos, e transformados em lixo e a sua destinação inapropriada. Os resíduos domésticos e industriais vêm acarretando sérios problemas, como as constantes mudanças climáticas, o assoreamento de rios e entupimento de bueiros ocasionando degradação de rios urbanos e outros cursos hídricos, aumento de enchentes, a destruição de áreas verdes, desequilíbrio do ecossistema e interferência nos serviços ecossistêmicos, mau cheiro e proliferação de moscas e outros animais indesejáveis, além de contribuir com a ocorrência de inúmeras doenças. É impossível resolver os problemas ambientais e reverter suas consequências sem que ocorra uma mudança nos sistemas de conhecimentos, nos valores e nos comportamentos gerados pela economia do desenvolvimento (Jacobi, 2003). Neste sentido, seria necessário haver mudanças no modo de pensar e agir das pessoas, e a educação tem papel fundamental na construção de uma postura mais ética, responsável e solidária das pessoas para com o meio ambiente (Gomes, 2006).

Nos Parâmetros Curriculares Nacionais (1998) é evidente a importância de se trabalhar nas Escolas a sensibilidade e a responsabilidade das nossas gerações pela manutenção e conservação de um meio ambiente equilibrado. O conceito de sustentabilidade com o reuso de materiais recicláveis pode ser abordada em sala de aula de forma transdisciplinar e lúdica. Um exemplo prático é apresentar o problema da utilização de garrafas PET (Politereftalato de Etileno) e as principais formas de reutilização, demonstrando aos alunos que o tratamento desses resíduos significa diminuir pela metade o consumo de energia, o lixo e a poluição gerada.

Layrargues (2002) defende uma redução do consumo priorizando reutilização, que deve ser priorizada sobre a reciclagem, pois esta gera uma falsa segurança, camufla a crítica ao consumismo e, além de tudo, reforça as estratégias de concentração de renda, ou seja, recicla-se para não se reduzir o consumo. 
A iniciativa de projetos de horta escolar é uma oportunidade transformadora para mudanças de hábitos alimentares e estabelecimento de comportamentos mais conscientes quanto ao ambiente que o aluno está inserido. De acordo com Morgado e Santos (2009):

A horta escolar pode ser um laboratório vivo que possibilita o desenvolvimento de diversas atividades pedagógicas em educação ambiental e alimentar, unindo teoria e prática de forma contextualizada, auxiliando no processo de ensino aprendizagem e estreitando relações através da promoção do trabalho coletivo e cooperado entre os agentes sociais envolvidos (Morgado \& Santos, 2006, p. 45).

Ribeiro et al. (2019), também corroboram:

A horta escolar é um lugar vivo que permite o desenvolvimento de diversas atividades pedagógicas em educação ambiental e alimentar unindo teoria e prática. $\mathrm{O}$ contato com a natureza é uma experiência muito válida para crianças e adolescentes. Ao montar uma horta na escola, professores de todas as áreas poderão trabalhar os mais variados temas. Assim como, os alunos são sensibilizados sobre a importância em manter o ambiente da escola limpo e organizado evitando a deposição de lixo e outros objetos pelas dependências da escola. São discutidas ações humanas conscientes de uso do meio ambiente, sempre incentivando os alunos a usarem esses conhecimentos e práticas nas suas casas e no meio onde vivem (Ribeiro et al. 2019, p. 540).

O ensino de ciências por investigação vem sendo abordado no trabalho escolar através de uma perspectiva da prática e tem atuação dentro do ensino no qual se estabeleceu a partir de novas leituras, ações e discussões sobre dados e informações que sejam coletados por meio das mais diversas estratégias (Carvalho, 2013). Segundo a mesma autora, a experimentação é uma metodologia específica, mais relacionada com o teste de hipóteses, enquanto a exploração permite o uso de diversas estratégias para coleta, organização e sistematização dos dados e informações relevantes que poderão se constituir como evidências para a construção de explicações que respondam às questões levantadas. Nesse sentido, o ensino por investigação é mais do que uma estratégia didática ou uma metodologia de ensino, é uma perspectiva de ensino ou uma abordagem didática em que as estratégias utilizadas servem ao propósito de possibilitar a realização de uma investigação pelos estudantes por meio da mediação do professor (Sasseron, 2015).

A utilização de diversas estratégias didáticas na perspectiva do EnCI (Ensino de Ciências por Investigação) pode contribuir para o desenvolvimento de visões mais adequadas sobre as diversas formas de produção de conhecimento científico, além de contemplar diversos perfis de alunos e estilos de ensinar (Scarpa \& Silva, 2013).

Destaca-se o objetivo geral deste estudo: apresentar a implantação de uma horta na escola, avaliando sua aplicabilidade como estratégia de ensino voltado para a educação ambiental e alimentação saudável. Para tanto, destacamos as pautas específicas do projeto que se atenuam para a discussão deste estudo:

- Planejar a implantação da horta no âmbito escolar;

- Buscar materiais alternativos e de baixo custo para a construção da horta;

- Demonstrar aos estudantes a relação entre a construção de uma horta com a questão ambiental, adotando práticas sustentáveis que envolvam o consumo consciente e a reutilização de materiais recicláveis.

- Estimular a socialização e o trabalho em equipe, respeitando os limites de cada aluno.

- Desenvolver as atividades de modo interdisciplinar e transdisciplinar através do tema abordado.

- Identificar a importância de reduzir, reutilizar e reciclar;

- Desenvolver bons hábitos alimentares, estimulando o consumo de alimentos saudáveis sem agrotóxicos e melhorando a qualidade de vida. 


\section{Metodologia}

Este estudo caracteriza-se por uma pesquisa descritiva, que pauta um Relato de Experiência em delineamento qualitativo acerca de um projeto exitoso na Educação Ambiental.

Mussi, Flores e Almeida (2021, p. 65) tecem acerca do Relato de Experiência:

$\mathrm{O}$ Relato de experiência é um tipo de produção de conhecimento, cujo texto trata de uma vivência acadêmica e/ou profissional em um dos pilares da formação universitária (ensino, pesquisa e extensão), cuja característica principal é a descrição da intervenção. Na construção do estudo é relevante conter embasamento científico e reflexão crítica.

O projeto de horta sustentável foi desenvolvido no espaço educacional da Escola Municipal Marquês de Tamandaré, localizada no bairro Nova Aliança na cidade de Ladário-MS. A instituição funciona nos três turnos: no matutino com as séries iniciais até o quinto ano, vespertino com fundamental II e no período noturno o espaço é cedido para o ensino médio estadual.

O projeto iniciou-se em abril de 2017, sendo apresentado a toda comunidade escolar como forma de oficina de ciências, denominado "Sementes do futuro". O projeto envolveu pesquisas bibliográficas sobre as práticas pedagógicas voltadas para a educação ambiental.

A amostragem envolveu todos os alunos matriculados na $6^{\circ}$ ao $9^{\circ}$ ano do Ensino Fundamental II da Escola Municipal Marques de Tamandaré. As aulas ministradas na disciplina de Ciências da Natureza compreendiam duas aulas semanais, possibilitando a utilização de uma hora semanal para cada turma realizar as atividades teóricas e práticas.

Para o desenvolvimento da pesquisa de horta sustentável, foi sugerido um acompanhamento através de um planejamento com diversas ações subdivididas durante os anos letivos de 2017 e 2018. Essas ações variavam entre atividades teóricas e práticas, através de uma abordagem qualitativa de acordo com Minayo et al. (2007), complementada com observações de cada etapa de trabalho e atividades lúdicas (pinturas de garrafas pet, modelagem de canteiros, entre outros) realizadas no decorrer dos ciclos do projeto. Para potencializar o entendimento dos alunos sobre o tema e estimular a participação deles nas atividades foram desenvolvidas as seguintes ações:

a) Apresentação do projeto: Em abril de 2017 foi realizada uma reunião com a gestão escolar, onde foram apresentadas as ideias e objetivos do projeto da horta escolar, como uma proposta para avaliação na disciplina de Ciências da Natureza. Ao ser analisado pela gestão, discutiu-se os espaços propícios para a instalação da horta e levantamento de recursos financeiros disponíveis para a compra dos materiais necessários, como ferramentas e sementes. O espaço físico para o desenvolvimento do projeto foi definido após visita da direção, da coordenação, da professora responsável pelo projeto e dos professores de outras disciplinas, que também contribuíram com sugestões de como o projeto poderia atrair um bom aproveitamento em suas disciplinas. Após essa etapa, foi feito uma análise do local escolhido quanto à adequabilidade e correção de possíveis problemas, como a luminosidade natural disponível, umidade, qualidade do solo, entre outros.

b) Apresentação do projeto aos alunos: A segunda ação da pesquisa ocorreu ainda no início do mês de abril de 2017. O projeto foi apresentado aos alunos, através de aula expositiva, onde surgiram várias sugestões para implementação da horta e sobre a adoção de práticas sustentáveis que envolvem o consumo consciente e a reutilização de materiais recicláveis. Ficou combinado que todos os alunos teriam que realizar todas as etapas das atividades com comprometimento, tendo como exemplo dentre as ações propostas, a coleta de garrafas-PET. A captação de doações de garrafas pets (Fig.1) envolveu a colaboração dos moradores do bairro. Dessa forma, além de envolver a comunidade local, os alunos repassavam os conhecimentos adquiridos durante as aulas sobre coleta seletiva e a importância de reduzir, reciclar e reutilizar garrafas pet. Posteriormente, as garrafas coletadas passaram por uma 
triagem e foram armazenadas em um local limpo e seguro para futura reutilização. Essas garrafas foram utilizadas para a confecção de uma sementeira ecológica suspensa para a fase inicial das plântulas e para a contenção dos canteiros. Além disso, esses materiais plásticos foram preparados e transformados pelos alunos, que usaram sua criatividade, colorindo-as com água e tintas xadrez de cores diversas.

Figura 1. Coleta seletiva das garrafas pet.

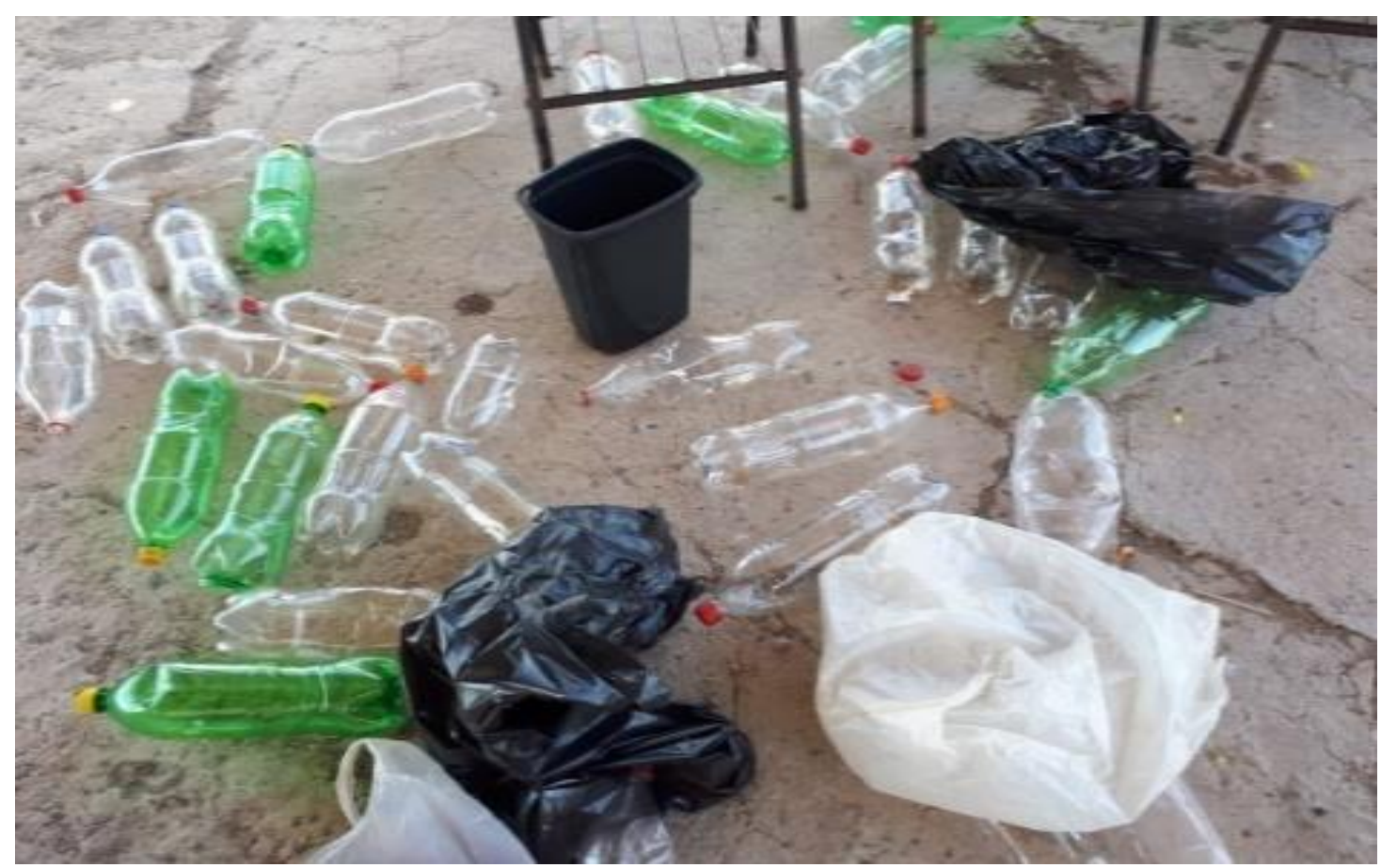

Fonte: Autores.

c) Instalação da horta: A terceira ação da pesquisa foi na metade do mês de abril, período destinado aos trabalhos que envolveram primeiramente a limpeza do local, retirada de entulhos e plantas daninhas, e depois o ajuste das medidas e espaçamentos da horta (Figs. 2 e 3). Essa ação foi realizada pelos alunos dos $8^{\circ}$ e $9^{\circ}$ anos do nível fundamental II (Fig. 2). Nessa etapa, foram feitos cercados de tela em aço, postes de aço e mourões de concreto fixados no solo com cimento (Fig.3). Logo após a conclusão dos cercados, os alunos iniciaram os trabalhos de abertura de valas para a montagem dos respectivos canteiros, com a utilização de garrafas pets de dois litros, cheias de água e posteriormente colorida com tintas xadrez, para torná-los mais atrativos. Aos alunos do $6^{\circ}$ e $7^{\circ}$ ano, o trabalho proposto foi a preparação do solo. Foram utilizadas caixas de madeira e garrafas pets na forma de hortas suspensas, com a finalidade de que houvesse um cuidado maior com as sementes na fase de germinação, para posteriormente acompanhar o crescimento das plântulas até a fase de transplante para os canteiros da horta. As hortaliças selecionadas foram: cebolinha, salsa, coentro, alface, couve, rúcula, mostarda, pimentão, tomate cereja, rabanete, cenoura, beterraba. As sementes foram doadas pela Secretaria Municipal de Agricultura do município de Ladário-MS. 
Figura 2. Trabalho de limpeza do terreno e montagem dos cercados.

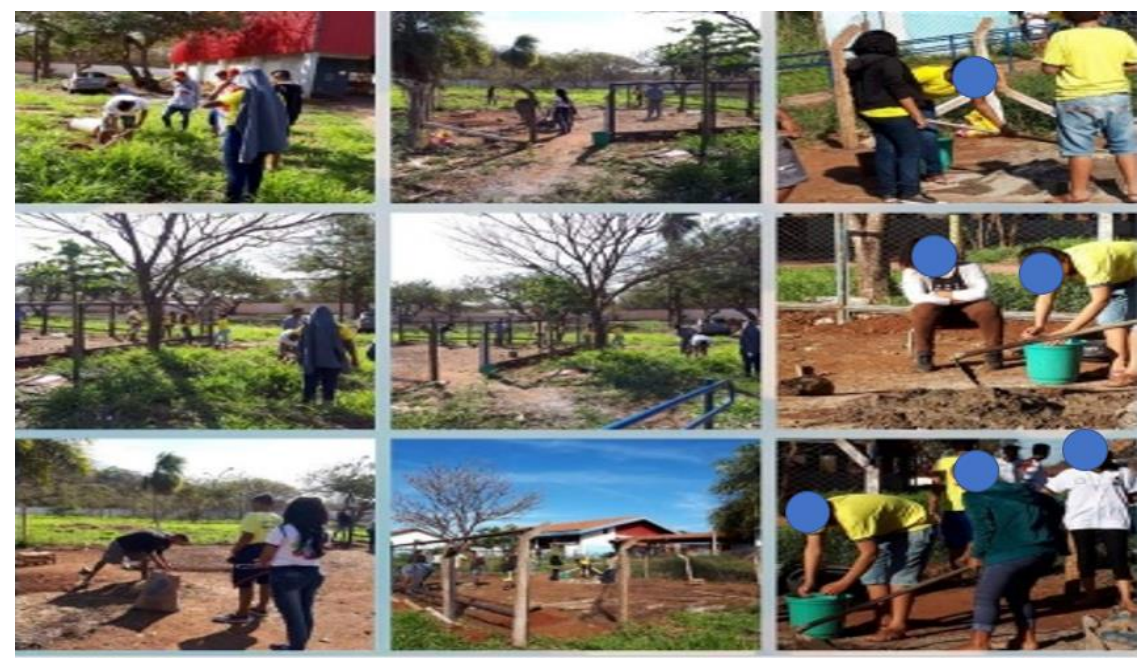

Fonte: Autores.

Figura 3. Trabalho de limpeza do terreno e montagem dos cercados.

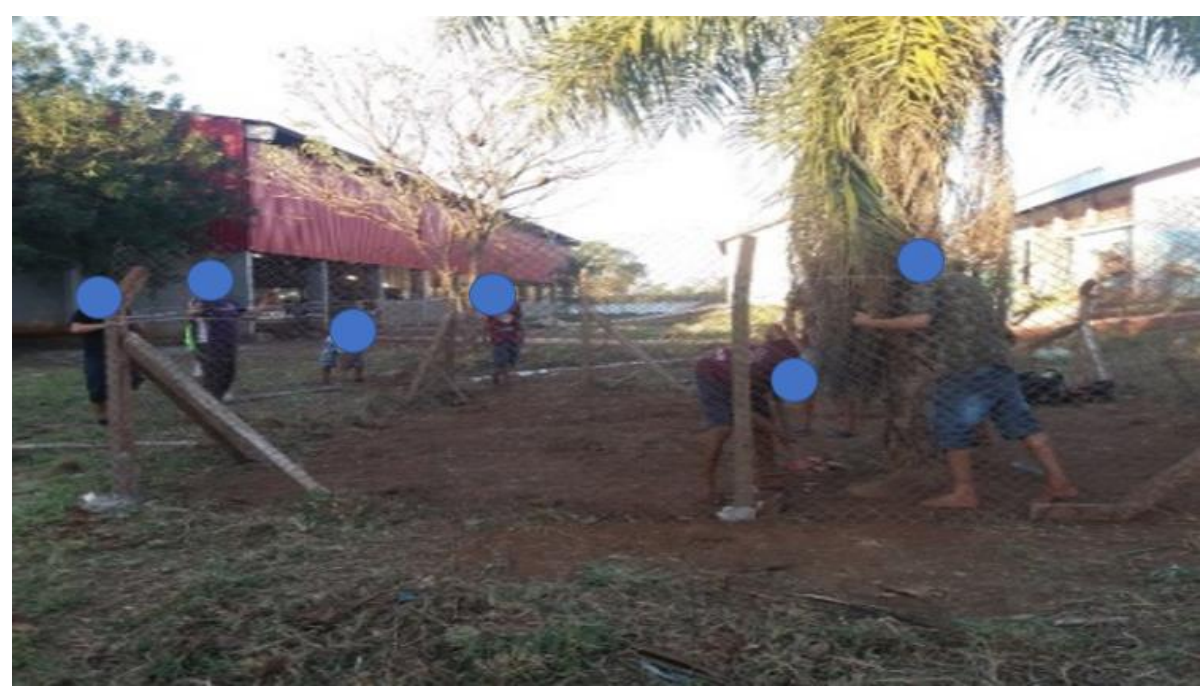

Fonte: Autores.

\section{Resultados}

Os resultados obtidos foram satisfatórios, pois durante todo o processo de execução do projeto, durante a aula semanal destinada à execução da horta, todos os alunos se envolveram, e cada atividade foi monitorada e fotografada ao longo do processo.

\subsection{Preparação do solo}

Antes da preparação do canteiro, foram feitos questionamentos sobre aspectos físicos, químicos e biológicos do solo. Após análises, constatou-se a necessidade de uso de matéria orgânica (Fig. 4), que foi adquirida através de uma parceria com a direção da escola. O adubo natural, constituído de uma mistura de compostagem e esterco, teve como finalidade o enriquecimento do solo e melhoramento da qualidade das hortaliças. O adubo foi adicionado nas sementeiras (Fig.5) e também utilizado nos canteiros juntamente com a técnica de compostagem, realizada através de resíduos orgânicos (cascas de frutas e verduras) separados da cozinha. 
Figuras 4 e 5. Mistura de compostagem com esterco; Utilização do produto adquirido.

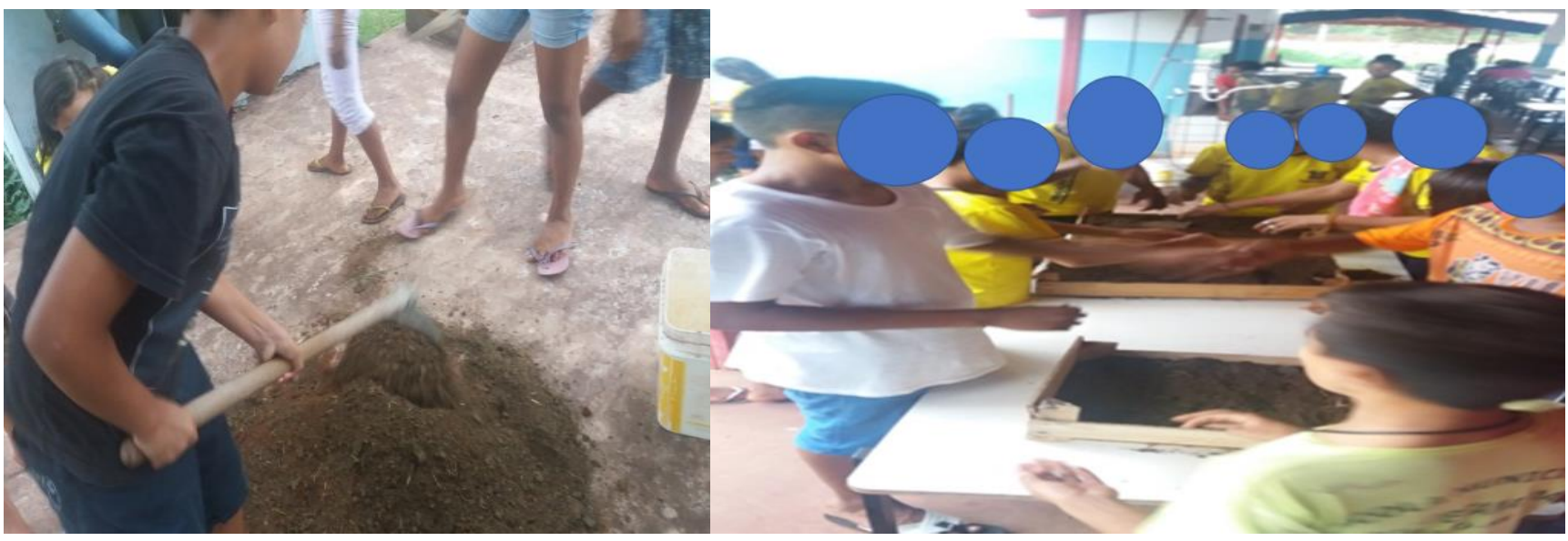

Fonte: Autores.

\subsection{Sementeira}

No processo de germinação das sementes para se obter as mudas de hortaliças, foram utilizadas sementeiras ecológicas, como caixa de madeira, caixa de leite e garrafas-pet (Fig. 6). Devido ao fato de as sementes das hortaliças serem sensíveis e pequenas, foram empregados certos cuidados especiais, como solo peneirado e rico em nutrientes, regas diárias, sol indireto e profundidade adequada do semeio.

Figura 6. Técnicas de sementeiras ecológicas.
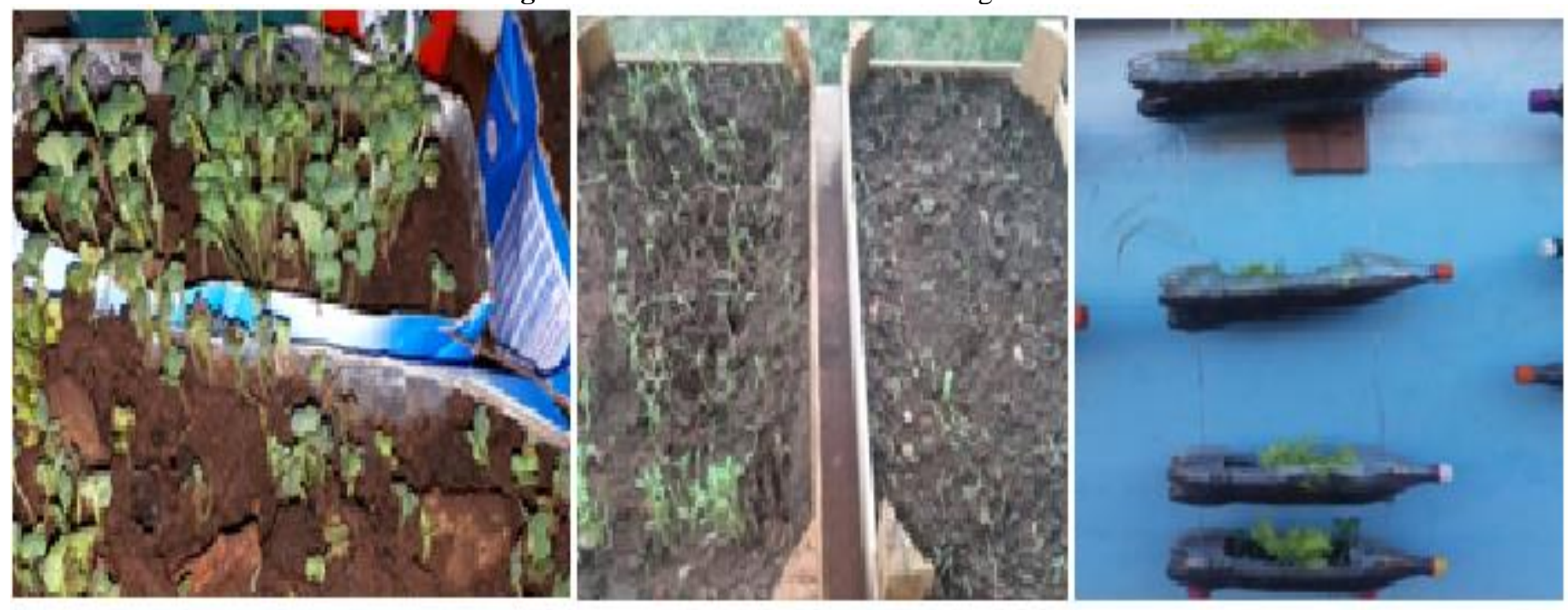

Fonte: Autores.

\subsection{Confecção dos canteiros}

Os canteiros foram delimitados com linha de barbante posicionados com cerca de $1 \mathrm{~m}$ de largura, com aproximadamente $20 \mathrm{~cm}$ de altura e separados por 30 a $40 \mathrm{~cm}$ entre si, com espaçamento de 1 a $1,5 \mathrm{~m}$ para facilitar a passagem e espaço para o trabalho dos alunos durante o desenvolvimento das atividades propostas (Figura 7). Garrafas-pet, vista como um dos inúmeros problemas causados pelo acúmulo de lixo daquela localidade, foram utilizadas para a contenção dos canteiros, e a coleta das mesmas foi bastante aceita e utilizada. As garrafas-pet foram dispostas com os gargalos para baixo, em pequenas valas de 15 a $20 \mathrm{~cm}$ no chão, delimitando os canteiros e evitando a perda do solo preparado, ocasionado pelas chuvas (Figura 8). 
Research, Society and Development, v. 11, n. 2, e55611225878, 2022

(CC BY 4.0) | ISSN 2525-3409 | DOI: http://dx.doi.org/10.33448/rsd-v11i2.25878

Figura 7. Delimitação dos canteiros e escavação das valas.
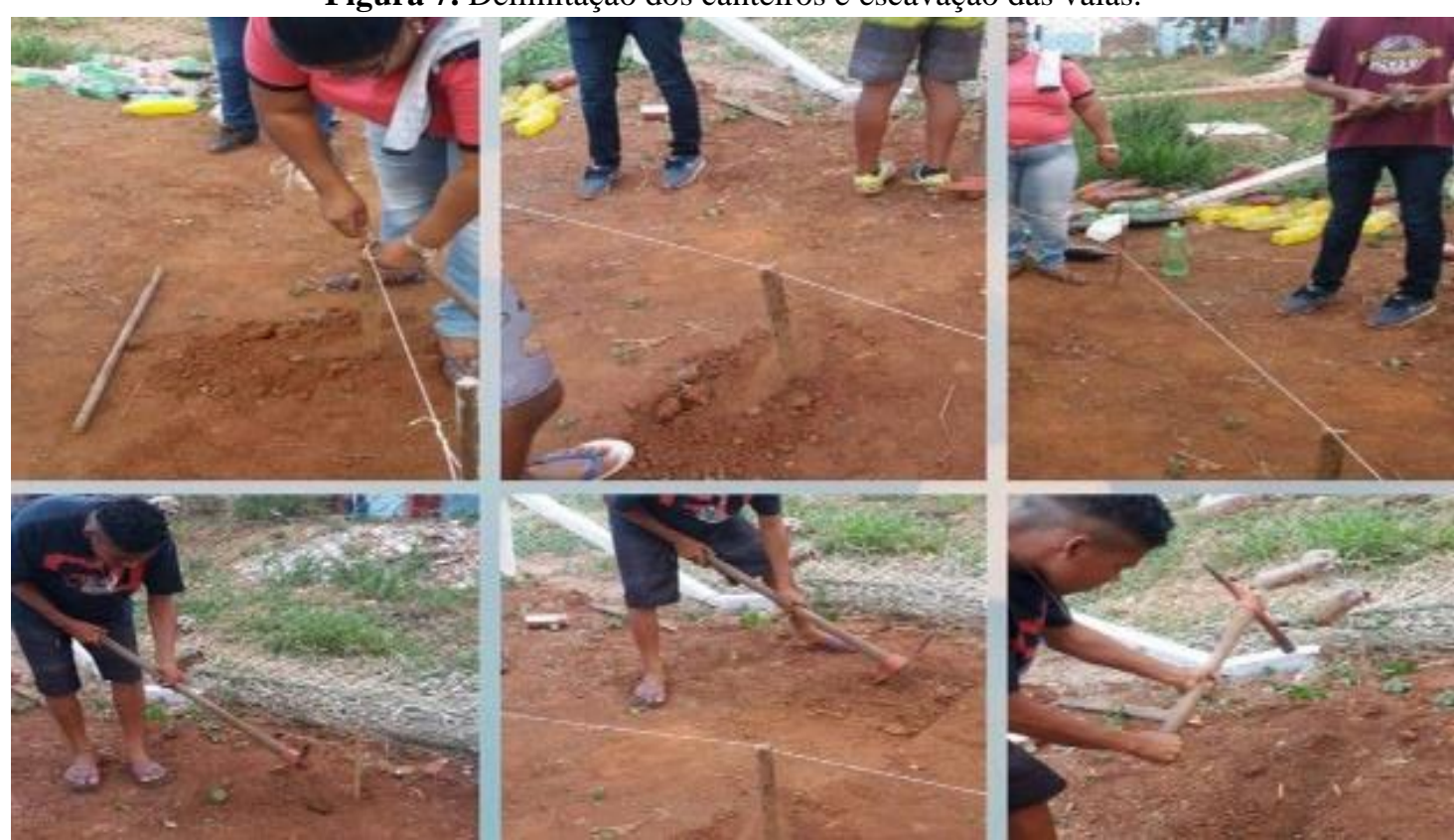

Fonte: Autores.

Figura 8. Posicionamento das garrafas.

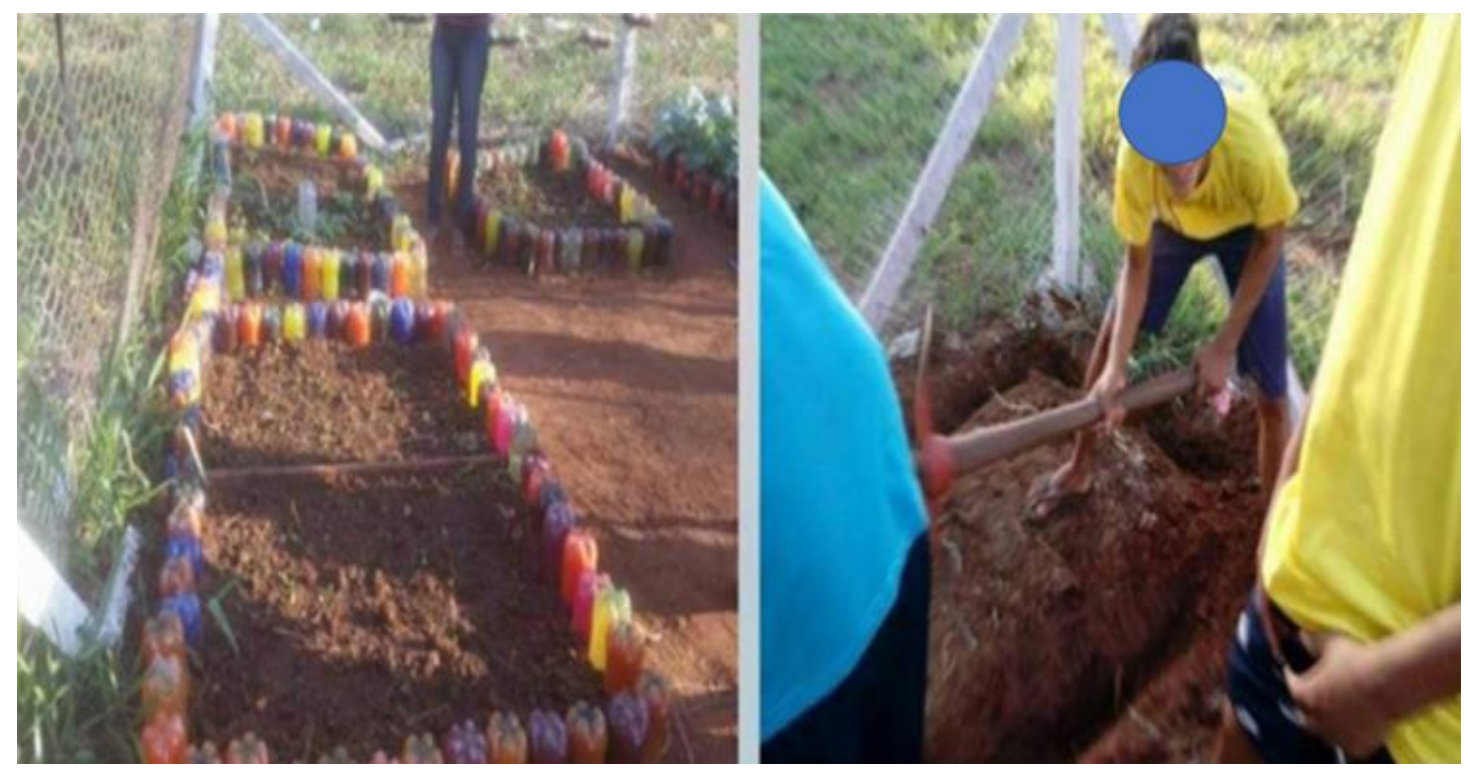

Fonte: Autores.

\subsection{A composteira}

A compostagem contou com o apoio das funcionárias da escola quanto à separação dos alimentos orgânicos, que seriam destinados ao lixo. Foi exposto aos alunos como ocorre os processos de decomposição dos alimentos no processo da compostagem. Após essa orientação, os alunos coletavam esse material a cada três dias e colocavam em uma espécie de composteira provisória, um buraco com medidas de 1,5 m de profundidade e $1 \mathrm{~m}$ de largura no solo feito em um local afastado, no qual foi depositado o material separado vindo da cozinha, e coberto com restos de folhas secas, esterco e um pouco e terra retirada do mesmo buraco, sendo posteriormente protegida com uma telha de Eternit. O material resultante era utilizado nos canteiros misturado com esterco. 


\subsection{A irrigação}

Para a irrigação, foram utilizados três métodos como alternativas conscientes, baseando-se principalmente quanto à utilização responsável sobre a disponibilidade e o desperdício de água. Os três métodos foram empregados de forma intercalada: a) irrigação com água tratada advinda da rede de distribuição, b) utilização da água desperdiçada pelos alunos provenientes dos bebedouros, ambas sendo dispersas nos canteiros por meio de regadores utilizados pelos alunos, e c) método de gotejamento, reutilizando garrafas pet de 3 litros e frasco de 5 litros de água mineral (Figura 9). Houve também a preocupação sobre disponibilidade de água em quantidade suficiente para o crescimento radicular das plântulas e para a atividade de microrganismos na fertilização do solo.

Figura 9. Irrigação por método de gotejamento.
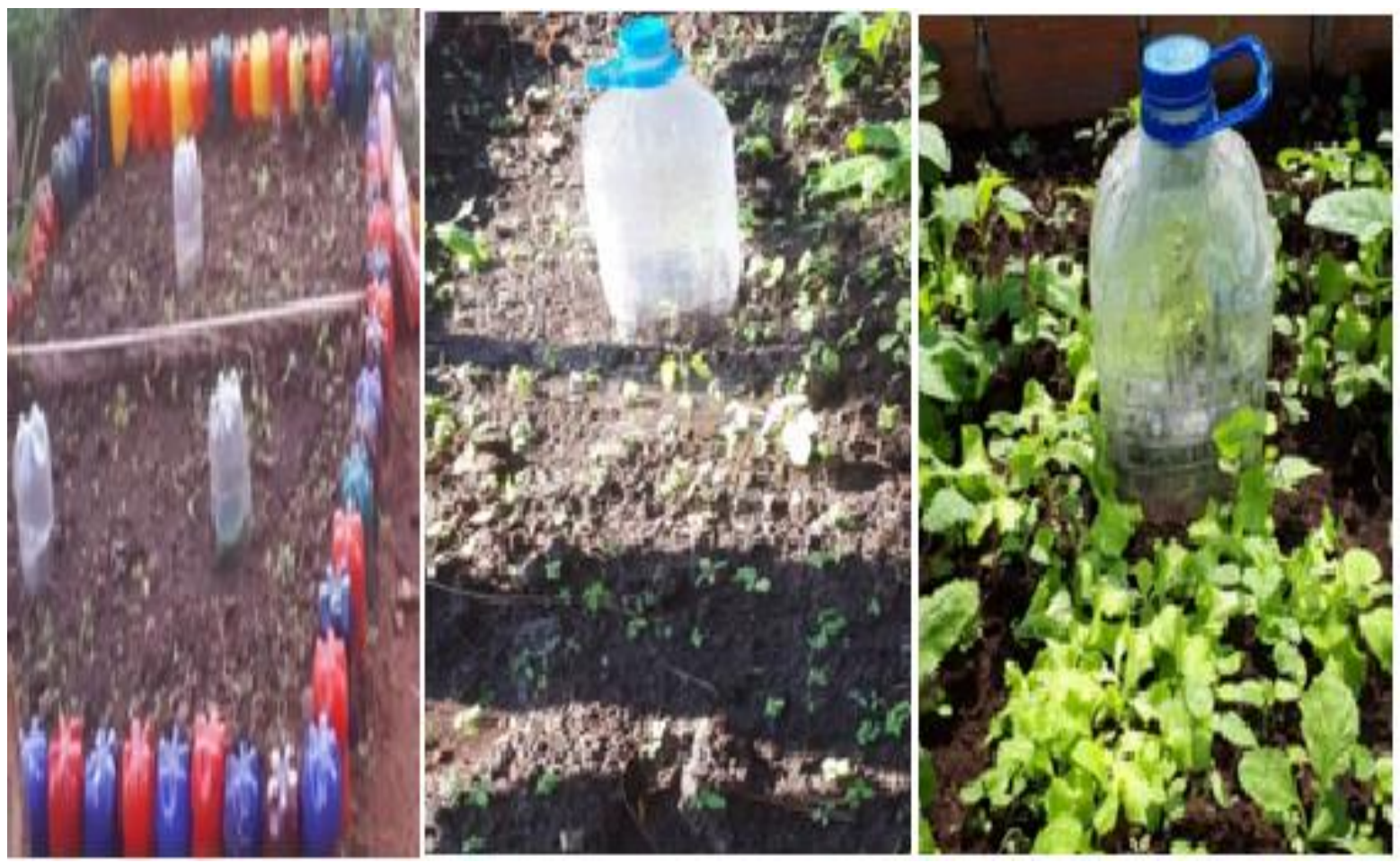

Fonte: Autores.

Durante o processo de instalação e desenvolvimento da horta, foram inseridas aulas teóricas e práticas propostas nos livros didáticos adotados no ano letivo, como: a preparação do solo, o processo de germinação, plantio e colheita, fungos e bactérias, degradação do meio ambiente, poluição, entre outros materiais como recursos pedagógicos que auxiliam o professor no processo de ensino e aprendizagem. Os produtos da horta, além de serem destinadas ao consumo na merenda diária, também foram distribuídos aos alunos, para consumo em suas residências, no intuito de incentivar a todos o hábito de uma alimentação saudável, evitando o desperdício de alimentos e a necessidade de valorizar o meio ambiente.

$\mathrm{Na}$ finalização das atividades, com os objetivos alcançados, os resultados foram apresentados a toda comunidade escolar através de uma culminância, onde os alunos utilizaram receitas culinárias originadas da horta, como bolos, sucos detox, saladas, entre outros. Toda a ação foi registrada por meio de fotos para atestar a finalização do projeto, que foi bem-sucedido. O resultado desse projeto foi apresentado ao município, através da Secretaria de Educação de Ladário (SMEL), na apresentação dos trabalhos desenvolvidos nas escolas municipais de Ladário, no ano de 2018, onde foi premiado com o $1^{\circ}$ lugar a nível fundamental II no "Prêmio Mara Estela Mônaco" como professora destaque do ano de 2018 (Figura 10). 
Figura 10. Imagem da premiação $1^{\circ}$ lugar "Prêmio Mara Estela Mônaco".

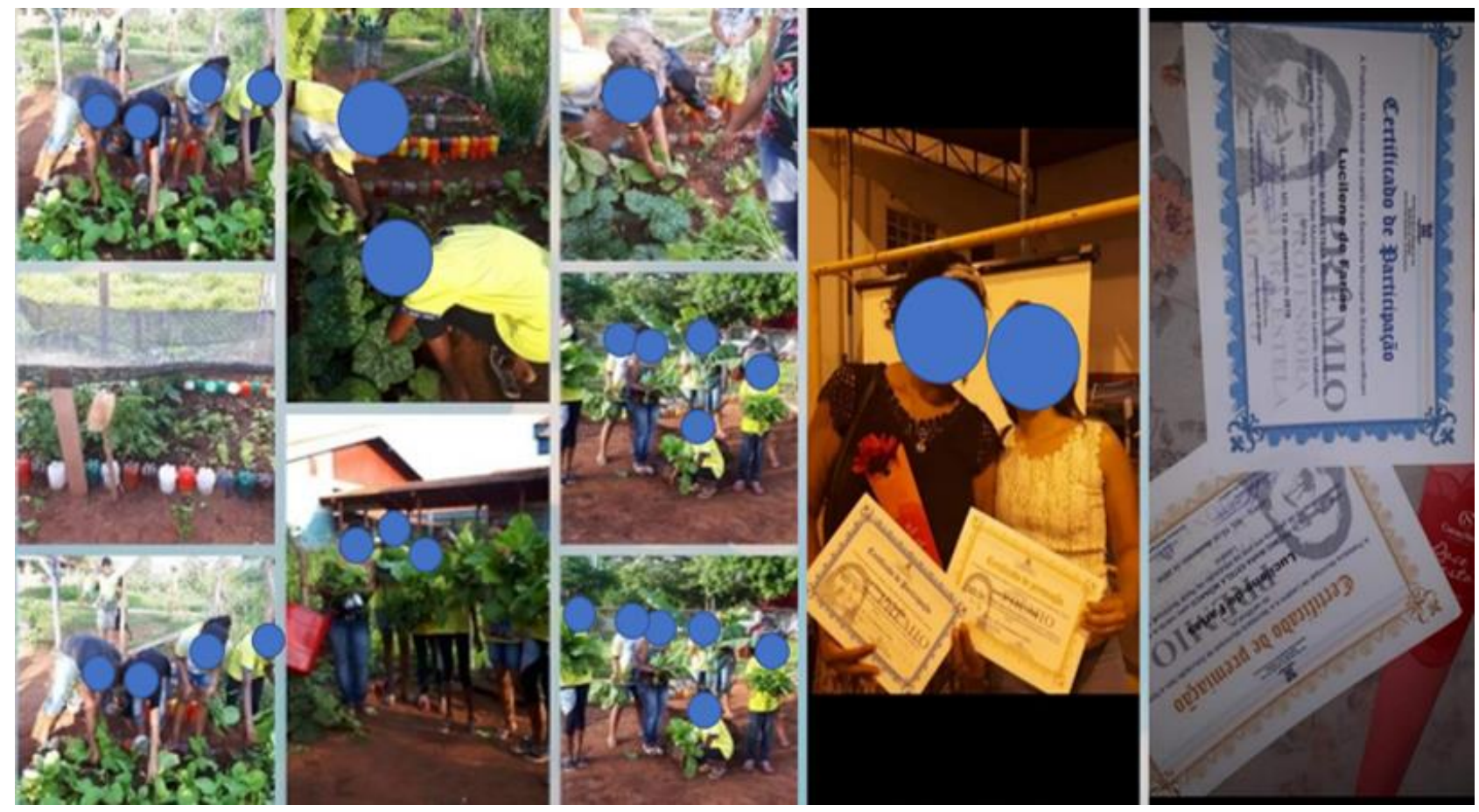

Fonte: Autores.

\section{Discussão}

Horta Escolar é uma sala de aula viva, concreta, dinâmica, inclusiva e demonstra que é possível promover uma educação integral, de maneira que proporcione descobertas e aprendizagens múltiplas com o trabalho interdisciplinar. Projetos de prática ambiental na forma de pesquisa-ação tem como propósito apresentar a Educação Ambiental como campo de estudo e pesquisa fundamental para a construção da consciência ecológica, além de tornar o estudo mais prazeroso, possibilitando ações educativas na perspectiva da construção de valores que contribuam com a constituição da cidadania.

Ao longo do ano letivo de 2017 e 2018, através dos registros das imagens fotografadas durante as aulas e de rodas de conversas, observou-se nitidamente a aceitação e envolvimento do corpo escolar (alunos e professores) no desenvolvimento do projeto, bem como a absorção da aprendizagem dos alunos de acordo com os objetivos apresentados. A horta escolar pode ser uma ótima estratégia pedagógica, tendo em vista que além de tirar os alunos do ambiente fechado da sala de aula, apoia-se no desenvolvimento da capacidade de trabalho em grupo, possibilitando o contato direto com o meio ambiente e diversos aprendizados através das aulas de campo. Importante destacar também que o trabalho coletivo tende a ser produtivo, pelo ato de dividir-se em grupos para a realização das tarefas. Outro resultado interessante que pôde ser observado e deve ser destacado foi a ideia de levar o conhecimento para seus familiares, vizinhos, pessoas do bairro, incentivando à reciclagem e redução de materiais descartáveis, bem como o incentivo em consumir alimentos orgânicos, métodos de se fazer um adubo natural, etc.

Durante a execução do projeto, observaram-se as muitas vantagens com a aplicação da abordagem que procurou utilizar como elementos que fazem parte da realidade do aluno, sobretudo, por tratar-se de algo relacionado às atividades práticas que irão intermediar com os conteúdos da sala de aula e que certamente serão ampliados ao cotidiano. Os principais conteúdo do nível fundamental II, que geralmente são abordados de forma teórica, pôde ser trabalhado na prática, como o estudo sobre os elementos contidos em fertilizantes, vantagem e desvantagens na sua aplicação na horta sustentável, tratamento da água e a higienização correta dos alimentos cultivados. Nas atividades diárias, os alunos foram capazes de identificar alguns problemas ambientais que o excesso de resíduos descartados (garrafa-PET) pode causar ao meio ambiente na relação entre sociedade, natureza e economia, além de adotarem hábitos de sustentabilidade que utilizem a reciclagem de garrafas-PET. 
Outro fato interessante que se destaca foi a ideia de levar o conhecimento obtido para seus familiares, vizinhos, pessoas do bairro, incentivando à reciclagem e redução de materiais descartáveis, bem como o consumo de alimentos orgânicos, cultivados em hortas comunitárias, livres de pesticidas, além de métodos de se fazer um adubo natural, etc. Dentro desse contexto, foi possível a utilização dos métodos aplicados de forma consciente, sobre a importância da reciclagem e reutilização de garrafas-PET, mostrando-lhes alternativas para reutilizarem materiais que seriam depositadas em lixo comum, diminuindo assim a quantidade de lixo e alguns impactos ambientais provenientes do descarte em locais incorretos.

Importante destacar que o trabalho coletivo foi eficaz para a realização das tarefas, pois os alunos mostraram-se interessados e comprometidos na construção e execução da horta sustentável, se empenhando de modo disciplinar, aprendendo a respeitar as diferenças, respeitando os níveis de aprendizagem que cada um consegue absorver e adquirindo conhecimentos de forma prática e prazerosa num ambiente natural, saindo do seu cotidiano da sala de aula e aprendendo o conteúdo de forma eficaz pela associação da teoria com a prática.

Para Maulin (2009), o processo de conhecimento e trocas de informações permite que os alunos interajam com a comunidade escolar, favorecendo o desenvolvimento participativo e a relação interpessoal de cada um. A interdisciplinaridade foi outro fator considerável nas atividades desenvolvidas na horta, pois se buscou a construção do conhecimento e um olhar voltado à ideia da natureza como sistema integrado. De acordo com Gadotti (2004), a interdisciplinaridade visa garantir a construção de um conhecimento globalizante, rompendo com as fronteiras das disciplinas. Nesse contexto compreende-se que a interdisciplinaridade é essencial para a atualidade da sala de aula, devido esta ser uma riqueza que insere qualidade na educação quanto às abordagens dos conteúdos pelos professores e a união de todos os participantes do processo educativo.

Conforme descrevem Silva, Veras, Soares, Rocha, Santos e Almeida (2016), a horta escolar...

[...] tem inúmeras contribuições, nos âmbitos ambiental, social e educacional, pois colabora para uma maior e melhor aproximação entre professores, alunos, pesquisadores e demais funcionários da escola, com isso, traz maior interatividade e aprendizado. Torna-se, portanto, uma experiência rica para todos que adentram no ambiente escolar (p. 344-345).

Outro importante aspecto a destacar é a importância de se obter parcerias com redes interessadas em projetos de hortas nas comunidades escolares como: EMBRAPA, UFMS, Prefeitura, Empresários, SANESUL. Essas e outras instituições podem ser interessantes fontes não só de patrocínio financeiro para realização de projetos para a compra de materiais necessários na utilização, mas também como redes de apoio entre seus pesquisadores e os professores coordenadores do projeto, na certeza de que essas parcerias poderão contribuir na solidificação de cada projeto em âmbito educacional.

\section{Considerações Finais}

Com base nos resultados obtidos, a inserção da horta escolar na vida dos educandos possibilitou uma mudança nítida de comportamento, uma vez que diariamente nos deparamos com um grande número de novas informações, inclusive nas salas de aula e em espaços externo da escola. Pode-se dizer que a horta contribui para um ensino e aprendizagem, tanto para inserção ao consumo das hortaliças como para uma consciência ambiental e sustentável, cabendo ao educador buscar informações especificas e mãos à obra na execução e manutenção das hortas, levando até ela princípios de horticultura orgânica, compostagem, formas de produção dos alimentos, o solo e a água como fonte de vida, relação campo-cidade, entre outros. Nessa visão os alunos participaram de forma coletiva e assídua com interesse, criatividade e motivação, o que de fato mostra que qualquer escola pode criar diferentes mecanismos que contribuam para a formação dos seus alunos e mantenham o compromisso das suas funções sociais. 
Outrossim, os produtos ricos em ensino e aprendizagem deste trabalho, não almejam encerrar-se por aqui. Pretende-se averiguar a importância de uma articulação deste projeto a partir da mobilização de conteúdos das disciplinas ministradas por diferentes docentes, e promover seminários integrados, pautando conceitos interdisciplinares com ênfase na pluralidade de conteúdos insurgentes à esta atividade.

\section{Referências}

Brasil. (1998). Parâmetros Curriculares Nacionais - 5 a $8^{a}$ série. Meio Ambiente. Ministério da Educação. MEC/SEF.

Brasil. (1981). Lei № 6.938, de 31 de agosto de 1981 - Dispõe sobre a Política Nacional do Meio Ambiente, seus fins e mecanismos de formulação e aplicação, e dá outras providências. 1981.

Brasil. (1999). Lei № 9.795, de 27 de abril de 1999 - Dispõe sobre a educação ambiental, institui a Política Nacional de Educação Ambiental e dá outras providências. 1999.

Capra, F. (2004). A Teia da Vida. Pensamento, 2004

Carpegiani, F. (2015). Escolas das redes pública e privada de SP contam como produzem adubo natural. Revista Educação, 1(216).

Carvalho, A. M. P. (2013). Ensino de Ciências por Investigação.: Condições para implementação em sala de aula. Cengage.

Carvalho, I. (1991). Ecologia, desenvolvimento e sociedade civil. Revista de Administração Pública, 25(4), 4-10.

Dias, R. (2011). Gestão ambiental: responsabilidade social e sustentabilidade. (2a ed.) Atlas.

Feiffer, A. H. S., Cunha, F. I. J., Benites, L. B., \& Dinardi, A. J. (2022). A falta de inserção do Parque Estadual do Espinilho enquanto espaço de formação ambiental. Revista Educar Mais, 6, 46-58.

Frizzo, M. N., \& Marin, E. B. (1989). O Ensino de Ciências nas Séries Iniciais. (3a ed.). Unijuí.

Gadotti, M., \& Barcelos, E. S. (2004). Construindo a escola cidadã no Paraná. Brasília: MEC (Cadernos Educação Básica).

Gouveia, N. (1999). Saúde e meio ambiente nas cidades: os desafios da saúde ambiental. Revista de Saúde e Sociedade. 8(1), 49-61.

Gomes, D. V. (2006). Educação para o consumo ético e sustentável. Revista eletrônica do Mestrado em Educação Ambiental, $16,18-31$.

Helle, L., Tynjälä, P., \& Olkinuora, E. (2006). Project-based learning in postsecondary education-theory, practice and rubber sling shots. Higher Education, 51(2), 287-314.

Jacobi, P. (2003). Educação ambiental, cidadania e sustentabilidade. Cadernos de Pesquisa, (118), 189-206.

Layargues, P. (2002). O Cinismo da Reciclagem. Cortez.

Levy, M. I. C. (2004). Escola ambientalizada e formacao de professor@s: compromissos e desafios. In: Taglieber, J. E., \& Guerra, A. F. S. (coord.) Pesquisa em Educação Ambiental: Pensamentos e Reflexões de Pesquisadores em Educação Ambiental. Editora Universitária.

Ribeiro, R. L., Almeida, R. S., \& Santos, C. J. S. (2019). O Programa Mais Educação e a horta escolar: perspectivas geográficas. Diversitas Journal, 4(2), $528-541$.

Maulin, G. C. (2009). O conhecimento intercultural: um diálogo com a educação ambiental. Rev. Bras. de Ed. Ambiental, 4, 60- 65.

Minayo, M. C. De S., Deslandes, S. F., Cruz Neto, O., \& Gomes, R. (2007) Pesquisa social: teoria, método e criatividade. (25a ed.). Vozes.

Morgado, F. S. (2006). A Horta Escolar na Educação Ambiental e Alimentar: experiências do projeto horta viva nas escolas municipais de Florianópolis. Centro de Ciências Agrárias. Universidade Federal de Santa Catarina, Florianópolis, 45p.

Mussi, R. S. F., Flores, F. F., \& Almeida, C. B. (2021). Pressupostos para a Elaboração de Relato de Experiência como conhecimento científico. Praxis Educacional, 17(48), 61-77.

Rodrigues, I. O. F.; Freixos, A. A. (2009). Representações e Práticas de Educação Ambiental em Uma Escola Pública do Município de Feira de Santana (BA): 66 subsídios para a ambientalização do currículo escolar. Rev. Bras. de Ed. Ambiental, Cuiabá, (4), 99-106.

Rodrigues, E. (2014). Ligados na pilha compostagem em escolas. Cartilha digital. http://www.efraim.com.br/cartilhasm.pdf

Sasseron, L. H.; Carvalho, A. M. P de. (2011). Alfabetização científica: uma revisão bibliográfica. Investigações em Ensino de Ciências, $16(1)$, 59-77.

Scarpa, D. L., \& Silva, M. B. (2013). A Biologia e o ensino de Ciências por investigação: dificuldades e possibilidades. In: Carvalho, A. M. P. de. (Orgs.). Ensino de Ciências por Investigação: condições para implementação em sala de aula. Cengage Learning, 129-52.

Serrano, C. M. L. (2003). Educação Ambiental e consumismo em Unidades de Ensino Fundamental de Viçosa-MG. 91f. Tese (Doutorado em Magister Scientiae) - Programa de Pós-graduação em Ciências Florestal, Universidade Federal de Viçosa, Viçosa. 
Research, Society and Development, v. 11, n. 2, e55611225878, 2022

(CC BY 4.0) | ISSN 2525-3409 | DOI: http://dx.doi.org/10.33448/rsd-v11i2.25878

Silva, F. S., Veras, G. da S., Soares, M. de A., Rocha, P. Q., Santos, J. R. da S., \& Almeida, R. S. de. (2016). Horta escolar agroecológica: alternativas ao ensino de Geografia e consciência ambiental no povoado Jardim Cordeiro, Delmiro Gouveia/AL. Diversitas Journal, 1(3), 337-346.

Silva, L. S., Camargo, F. A. O., \& Ceretta, C. A. (2000). Composição da fase sólida orgânica do solo. In: Meurer, E. J. Fundamentos de química do solo. Porto Alegre: Genesis. 45-62. 